\title{
Suspicion of neglect or abuse in two hospitalized cases (Case report)
}

\author{
Moersintowarti B. Narendra, Hardjono Soeparto, Yustina Rosanti, Agus Salim \\ Indonesian Society of Pediatrician, Faculty of Medicine/Dr.Soetomo Hospital Surabaya, Indonesia
}

\begin{abstract}
The convention of children's rights (1989) has acknowledged and recommended a statement that minimal standard for the child welfare with the range of primary right to keep an outstanding life for the children's development to their maximum potential, protecting from disturbances e.g. neglect and physical abuse.But, it is difficult to classify cases whether related to the problem of neglect or abuse, especially in developing countries where discrepancies in health services is remain exist.Objective : To present two cases which have been overlooked to the possibilities of abuse and neglect. Discription of the cases :Case 1. A malnourished 2 years old boy who was admitted with diarrhea in Dr.Soetomo Hospital Surabaya (September 6 ,1998) with :Clinical criteria of Marasmic Kwashiorkor available.lgnorance of health worker about nutritional status and inadequate referral system. 3. Factors related to the malnutrition are: a. Early weaning and inadequate weaning food. b. Poverty and low education. c. Lack of integrated health care (GOBI FFF practice). Case 2. An epileptic 11 years old girl was admitted in Dr.Soetomo Hospital Surabaya (July,12, 1999). Problems list were : Respiratory problem which could not be explained pathophysiologically. Single parent, and inconsistency of adequate childrearing, Factors related to the failure in compliance of epileptic treatment, and Isolation and restricted movement.Discussion of the difficulty in classification of the cases, and the possibility of solving the problem in Surabaya related to the limited action of the Committee on Child Protection, need to have positive suggestions sharing experience from the Congress members. [Paediatr Indones 2001; 41:115-119]
\end{abstract}

Keywords: child abuse and neglect, Indonesia.

Implementation of the "Convention on the Right of the Child" in Indonesia that was ratified in 1990 is still a big problem related to the willingness of people involved, and problems arising from child labours,street children,sexual exploitation, the weak laws for child protection. On the other hand, serious health problems that would interfere lots of underfive children e.g. malnutrition, recurrent infection, injury

Correspondence: Moersintowati B Narendra, M.D., Department of Child Health, Medical School, Airlangga University, Surabaya, Jalan Dharmawangsa, Surabaya, Indonesia. etc.are still exist in Developing countries included Indonesia. The acknowledgement and recommendation of convention of children's rights in 1989 stated that minimal standard for the child welfare with the range of primary right to keep an outstanding life for the children's development to their maximum potential, protection from disturbances e.g. neglect and physical abuse. ${ }^{1}$ Multicultural and ethnic differences, and the remain discrepancies in health services, make it more difficult to classify cases whether related to the case of abuse or neglect caused by economical or psychological background, or culturally accepted ?The purpose of reporting two cases with a suspicion of abuse or neglect, as learned lesson on the possibilities of overlapping ideas con- 
cerning social paediatrics point of view within the context of children's right .

\section{CASE REPORT}

\section{Case 1}

A two year old boy with main complaint of watery diarrhea about 10 times a day, was admitted to Dr. Soetomo Hospital on September 6, 1998. Before this hospitalization he got some episodes of illness such as diarrhea with yellowish foul smell ear discharge and edema on both legs one month before the admission.

This patient was regularly attended the local integrated mother and child health post named as Posyandu which was located nearby their house. But since the age of 7 months his mother got pregnant again, the child was seldom been brought to the Posyandu., and breastfeeding was stopped. And then the boy has been frequently suffering from upper respiratory tract infections and diarrhea about 5-6 times per month with the duration of 3-4 days. His appetite was not good and he often vomited after each feeding, as supplemental feeding he got sugar water instead of breastmilk, added with rice and banana twice a day.

After the age of 1 year he has been given sufficient family dish consists of rice, soup, etc. This patient was referred to Dr.Soetomo Hospital with 15 days fever and malnutrition by a general practitioner, but the parents did not comply for economical reason. Then the child was brought to a traditional healer who provided the family cheaper medication for a period of time. ${ }^{1}$

Observing the weight curve of the patient there is a normal curve from birth to 9 months old, even though mother got pregnant at 7 months and breastfeeding was stopped. The curve then began to falter after the age of 9 to 11 months. After 11 months they had visited the Posyandu on occasionally, then the curve was shown as dotted line, and we can see here that his weight tended to decrease and became worst at the age of 14-15 months (below the red line of KMS). But then no referral or further intervention had been mentioned by the parents until the age of 24 months when he was referred by a general practitioner doctor to Dr. Soetomo Hospital with severe malnutrition. The condition was very bad with clinical judgement of edema on the extremities, sunken eyes, reddish hair, and crazy pavement dermatosis respectively observed.

Based on history and physical examination, working diagnosis was Marasmic Kwashiorkor with chronic diarrhea, urinary tract infection, bronchopneumonia, chronic purulent otitis media, and anemia.For about 1 month he was treated with good result and showing catch up growth significantly, and was returned home with increased of body weight about $3.4 \mathrm{Kg}$., he could walk again and his speech developed. Regular follow up to the nutritional out patient clinic at Dr.Soetomo Hospital was done with provision of counseling and food supplementation.

\section{Case 2}

An eleven year old girl, was admitted in Dr.Soetomo Hospital on July 13, 1999 with main complaints of seven days dyspnea which was started with profuse vomiting, abdominal pain and headache. Within 7 days before admission she had suffered from swelling which was started from her face toward the whole body. There was decreasing urine production, but no history of fever or cold. On four days before admission she became weaker and she has to be supported on walking and joint pains were noted. Convulsion for about 5 minutes happened on one day after admission. She has had febrile convulsion since $31 / 2$ months old, and established as epilepsy at the age of seven when she was at the first grade of elementary school.Regular treatment with carbamazepine and pyridoxin has been stopped because of economical reason since June 1998, then she cotinue suffering from 3 to 4 times convulsion every month Family history as told by the mother are as follows ${ }^{2}$ :She is the third child of her mother with her biological father. Biological father died when the patient was a $3 \frac{1}{2}$ months old baby Mother remarried and she had another sibling.

Since the age of 4 months until the age of 9 years she lived with her father's brother family.Clinical problems were : dyspnea, vomiting, edema anasarca, tetraparesis,pericardial effusion, undernutrition and bad social history of having frequently punished by 
her uncle. Restriction of activities for about one year staying at home as advised by her teacher due to her frequent epileptic convulsion attacks and learning difficulties. ${ }^{2}$ Diagnosis on admission was : Acute Renal Failure, Epilepsy and undernutrition.Course of illness during 14 days of admission shows as a difficult case and unsolved respiratory and psychiatric problems.

\section{Discussion}

Lesson learned from these two cases that might be related to neglect or abuse is based on different point of view. First,it should be looked at the family background, secondly the health provider which are both strongly related to the norms of local culture. Case 1, basically the family was good health complier until a new pregnancy happened which was unfortunately not detected by the primary health provider at village level. Close birth spacing is actually one of the high risk in paediatrics that should be anticipated for early weaning.by health workers at any level. Further, problem of breastfeeding, inadequate supplemental and subtitutional feeding lead the baby into faltering of growth curve progressively until the worst malnuourished grade and he was admitted to the hospital. A teenage mother with two underfives in the house really needed a close guidance from the health provider.

Lack of monitoring and counselling demonstrated give two possibilities of explanations that have to be considered, first that the health provider might be ignorance of the paediatric risk which is not necessarily to be abusing the baby but more likely neglecting. Whether skill training on how to detect KMS deviation should be provided will be the problem solving and when to refer the nutritional high risk babies to the higher level of health care, this should be decided.A more realistic referral system regarding the weighing activities done by the women in the community should be developed as a package on monitoring the underfives. Case 2 is more about stigma on epilepsy happened to a previlleged girl of a single parent coping by an extended family system. Again, the ignorance of epilepsy as a non infectious disease and non inherited within a family is remain a big problem for community education. A serious medical advocacy on treating epileptic children is a guarantee to get the best compliance from the extended family.Single parenting is another problem that influenced more by educational and economical level in the community. Whether this abusing case was solved through law and order or careful counselling is an important step to be taken by a paediatrician 3,4

On national seminars at Yogyakarta in 1982 and then in 1999 the terminology of Child Neglect and Child abuse were used only related to violence. Accurate data are very difficult to be gathered in Indonesia, Yayasan Kesejahteraan Anak Indonesia (YKAI) compiled data from mass media and reported that an increasing tendency was noted. In 1994 about 172 cases, in 1995 about 421 cases, and in 1996 about 476 cases were reported. ${ }^{5}$ Basoeki L. cited from a study done at 6 big cities in Indonesia (Medan, Palembang, Semarang, Ujung Pandang and Kupang) related to the kind / type, location, source and condition that provoked to violence were noted as the following:Various physical violence was reported as the most prevalent in number, then followed by mental and sexual violence respectively. The highest prevalent cases were found in Semarang and Surabaya because these two big cities in Java becoming are more complex compared to the other big cities outside Java.Victims of child abuse happened more in boys than in girls in comparison of $2: 1$ or 55 : 45 .

Conditions that enhance violence toward children in general are devided into 3 categories:

1. Cultural conditions such as the high value on brave, strong and firm in facing difficulties which are associated to "manly characters". Norms that children should be loyal, and becoming economical value to their parents, teachers are always right and never doing wrong, limitations and restrictions places for activities in the cities, inadequate punishment for wandering street children who were prejudiced as doing more violence than others.

2. Social conditions such as common behavior to be drunk, gambling, and big cities society culture in Indonesia causing weakness in social control and formal rules.

3. Economical conditions in many poverty cases children are forced to help and not to be burden for 
TABLE 1. DISTRIBUTION OF ABUSERS' RELATIONSHIP WITH E ABUSED CHILD BY TYPE OF ABUSE ${ }^{3}$

\begin{tabular}{|c|c|c|c|c|c|c|}
\hline \multirow[b]{2}{*}{ Relationship } & \multirow[b]{2}{*}{ Physical } & \multicolumn{2}{|c|}{ Type of Abuse } & \multirow[b]{2}{*}{$\begin{array}{l}\text { Psycho- } \\
\text { logical }\end{array}$} & \multirow[b]{2}{*}{ Multiple } & \multirow[b]{2}{*}{ Tota } \\
\hline & & Sexual & $\begin{array}{l}\text { Gross } \\
\text { neglect }\end{array}$ & & & \\
\hline Parent & 144 & 37 & 12 & 10 & 24 & 227 \\
\hline Family member & 4 & 9 & 0 & 0 & 0 & 13 \\
\hline Step-parent & 14 & 12 & 1 & 1 & 4 & 32 \\
\hline Relative & 8 & 9 & 0 & 0 & 2 & 19 \\
\hline Caregiver & 7 & 2 & 0 & 0 & 2 & 11 \\
\hline Teacher & 1 & 5 & 0 & 0 & 0 & 6 \\
\hline Unrelated person & 4 & 64 & 0 & 0 & 2 & 70 \\
\hline Unidentified person & 0 & 19 & 0 & 0 & 0 & 19 \\
\hline Total & 182 & 157 & 13 & 11 & 34 & 397 \\
\hline
\end{tabular}

Cited from CPR Statistical Report,Hongkong.1998.

the parents which would propose the possibility of violence by the parents toward children.

Relationship of abusers with the abused child reported by Child Protection Registry (CPR) in Hongkong 1998 that $57 \%$ of the abusers involved in the newly registered child abuse cases were parents. A breakdown by type of abuse in table 1, indicated that majority of abusers were unrelated person in sexual cases while majority were parents in other four types of child abuse cases. Categories with the highest numbers are highlighted.

Manifestation of child abuse including physical abuse in $70 \%$ cases, and difficult to detect sexual abuse, and limited data either on nutritional or drug abuse, emotional abuse, and medical care neglect.

From several studies it was stated that almost $1 / 3$ of abused children had recurrent serious injuries, some of them death if they did not get adequate intervention. It is estimated that about $5 \%$ were killed and $35 \%$ suffered from serious injuries.

The spectrum of child maltreatment encompasses acts of commission,or abuse, and acts of ommission, or neglect, by caretaker that adversely affect children. The act can be physical or psychologic. The boundaries between these areas are indistinct and psychologic; physical abuse and neglect overlap and may exist at the same time or various times in the child's life (figure 2). Physical abuse

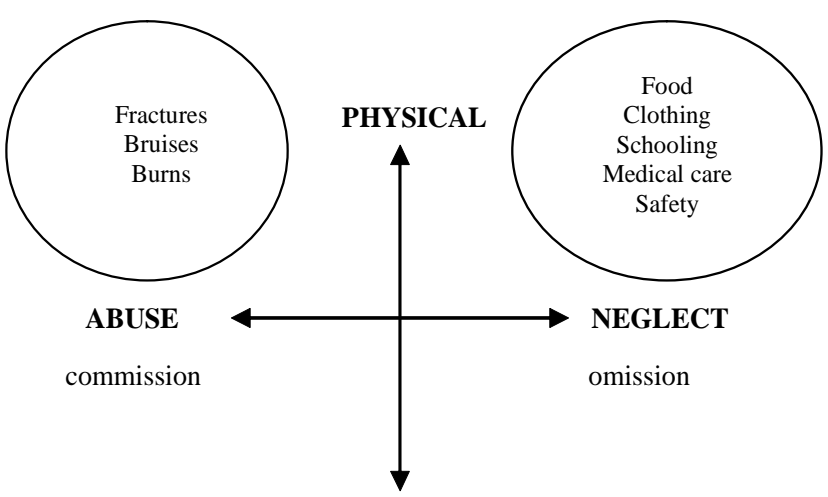

and neglect invariably have short and long term psychological consequences. Psychologic consequences may persist long after the physical wounds heal or recovery from the disease. ${ }^{4}$

Fontana (1973) as cited by Basoeki Lestari, suggested that itshould be noted for suspicion on child abuse :

- Appearance of fear to the parents

- A long time separation of a child.

- Skin disorders or bruises

- Malnutrition

- Unusual feeding or drugs

- Unusual winter clothing

- Frequent crying

- Very careful toward parents restrictions. 
Suspicion on child abuse should be based on evidence of clinical manifestations, when injury is unexplained, unexplainable, or implausible. If an injury is incompatible with the history given or with the child's development, suspected abuse should be reported . It is not necessary to have diagnostic certainty of physical abuse to file a report . ${ }^{4}$

A delay in seeking medical help should increase suspicion of abuse or neglect, the physician should determine whether the parents have an understanding of disease processes and intellectual, emotional, and physical resources needed to provide for their children. A delay may also be due to a lack of transportation or ignorance about the significance of disease or injury. (Charles F.Johnson, 2000).

From cases in this report, a certain consideration
Terrorize

Put down

Compare

Insult he effect of medical care negliger Love

the possibility of depression in case Support

uate intervention is important to $\mathrm{p}$ Recognize

proble PSYCHOLOGICAL Stimulate rovmg care observed trom grandmother stu anu operr ness for education matters give the opportunity of catch up growth and development. But on the other hand, case 2 is a high risk for recurrent mental injury and further effect on educational limitation.

Management of child abuse or neglect in the case of violence toward children in Indonesia is not established yet especially for a certain law for child protection. An approach to deal with child abuse and neglect had been proposed by The Indonesian Society of Pediatrician during the sixth Asean Pediatric Conference in 1992 to develop a solid National Children Foundation (Lembaga Anak) in Indonesia. ${ }^{6}$

At present there are NGO (non government organizations) regarding with child protection activity namely Lembaga Perlindungan Anak (LPA) at several big cities e.g. Surabaya, Bandung multidisciplinary developed.

As recommended in a seminar on Child abuse in
Yogyakarta 1999, against "Violence toward children" to build up a multidisciplinary working group of sectoral government departments and community participation.

Clinical manifestations as a screening instrument to detect the suspicion of child abuse or neglect should be introduced as the first priority, then a formal program should be developed to support the intervention which is determined by a definite law as a concrete ratification of the Convention of Children's right in Indonesia.

To establish Child Crisis Centers at every province and developing rehabilitation centers for the victims including the perpetrators in attempt to bringing them to a normal life, involvement of political organizations, relious sectors as well as community leaders is mandatory. ${ }^{\text {? }}$

\section{References}

1. Yustina Rosanti: Malnourished Child, neglected or abused ?, A case report, presented for thepurpose of educational requirement in Pediatric training, Dept. of Child Health, Faculty of Medcine, Airlangga University, 1999 (unpublished).

2. Agus Salim. A problem case of epilepsy presented for the purpose of educatioal requirement in Pediatric training, Dept.of Child Health Faculty of Medicine, Airlangga University; 1999 (unpublished).

3. Hongkong Child Protection Registry, Statistical Report, 1998. p 13.

4. Johnston Charles F. Abuse and neglect of children. Nelson Textbook of Pediatrics, Behrman Kliegman,Jenson., $16^{\text {th }}$ edition; 2000. p.110-111.

5. Basoeki Lestari S.Child Abuse dan dampaknya terhadap kesehatan (Child Abuse and the effect on Health)Buku :Child Abuse dan anak yang berkonflik dengan hukum, editor Bagong Suyanto dkk. Kerjasama Lembaga Perlindungan Anak (LPA) Jawa Timur, UNICEF dan POLDA Jawa Timur. 
6. Moersintowarti B.Narendra. Approach on Problems of Child Abuse and Neglect, Presented at The sixth Asean Pediatric Federation Conference, Denpasar Bali, October 21-24; 1992.
7. Ranuh,IG.N.Gde. Experience on child abuse in Indonesia, Presented at IPSCAN $5^{\text {th }}$ Asian Conference on Child Protection, Hong Kong 25-27 November 1999. 